\title{
Hasta Takip Sistemi'nin Osteoporozlu Hastaların Tedavi Uyumu ile Yaşam Kalitesi Üzerine Etkisinin Araştırılması
}

\author{
Effect of Patient Follow-Up System on the Treatment Compliance of Osteoporotic \\ Patients and on Quality of Life
}

Ercan Madenci, Erhan ibas*, irfan Koca*, Özlem Altındağ*

Medeniyet Üniversitesi Tıp Fakültesi, Göztepe Eğitim Araştırma Hastanesi, Fiziksel Tip ve Rehabilitasyon Anabilim Dalı, i̇stanbul, Türkiye *Gaziantep Üniversitesi Tıp Fakültesi, Fiziksel Tıp ve Rehabilitasyon Anabilim Dall, Gaziantep, Türkiye

\section{Özet}

Amaç: Osteoporoz tedavisi uzun zaman alabilen kronik bir hastalık olup, kırık riskini arttırmasından, sosyal, psikolojik, ekonomik ve fiziksel boyutları ile yaşam kalitesine olumsuz etkileri olmasından dolayı önemli bir halk sağlığı sorunudur. Hasta takip programının, ilaç uyumuna ve yaşam kalitesi üzerine etkisini araştırmayı amaçladık.

Gereç ve Yöntem: Çalışmaya 233 osteoporoz tanılı hasta alındı ve 200 hasta (173 postmenopozal osteoporozlu kadın, 27 senil osteoporozlu erkek) ile devam edildi. Günlük, haftalık ve aylık takip grupları olmak üzere hastalar 3 gruba ayrıldı. Hasta takip programı yardımıyla hastalar telefon ile arandı. Aylık Medikasyon Sahiplik Oranları hesaplandı. Başlangıç, 3. ve 6. aylarda Qualeffo-41 ile yaşam kalitelerine bakıldı.

Bulgular: Başlangıçtan itibaren 6 aylık süre içinde Medikasyon Sahiplik Oran düzeylerinde tüm gruplarda anlamlı artış saptandı ( $p<0,05)$. Aylık takip grubu diğerlerine göre en uyumlu grup bulundu. Yaşam kalitelerinde de anlamlı değişiklikler gözlendi $(p<0,05)$.

Sonuç: Hastaların kullanmış oldukları ilaçların doz aralıklarının özellikle uzun doz aralıklı ilaç rejimlerinin ve hasta ilaç hatırlatma programlarının uyum üzerine çok etkili olduğunu ve uyumun artması ile yaşam kalitesinin de daha iyi olacağını söyleyebiliriz. Tedavi uyumu bozulursa tıbbi zararlara, ekonomik kayıplara da neden olunabileceği unutulmamalıdır. (Türk Osteoporoz Dergisi 2014;20: 46-50)

Anahtar kelimeler: Osteoporoz, hasta takip programı, medikasyon sahiplik oranı, yaşam kalitesi

\section{Summary}

Objective: Osteoporosis is a chronic disease that can take a long time to treat and is an important public health issue since it increases the risk of fractures and it has negative effects on quality of life with its social, psychological, economic and physical dimensions. It was aimed to evaluate the effect of patient follow-up program on drug compliance and quality of life.

Materials and Methods: This study included 233 patients diagnosed with osteoporosis and the study was continued with 200 patients (173 females with postmenopausal osteoporosis, 27 males with senile osteoporosis). Patients were divided into 3 groups as daily, weekly and monthly follow-up groups. Patients were called by telephone with the help of patient follow-up program. Monthly Medication Possession Ratio (MPR) was calculated. Qualeffo-41 quality of life data were assessed at baseline, at the $3^{\text {rd }}$ and $6^{\text {th }}$ months.

Results: From the baseline within 6 months, MPR levels were significantly increased in all groups ( $p<0.05)$. Monthly follow-up group was found the most compatible group compared to others. Significant changes in quality of life were observed $(p<0.05)$.

Conclusions: Dose intervals, especially long dose interval regimens and patient drug reminder programs are highly effective on compliance and quality of life would be better as the compliance increases. It should be bear in mind that if treatment incompliance occurs it may lead to medical harms and economical losses. (Turkish Journal of Osteoporosis 2014;20: 46-50)

Key words: Osteoporosis, patient follow-up system, medication possession ratio, quality of life

Yazışma Adresi/Address for Correspondence: Dr. Ercan Madenci, Medeniyet Üniversitesi Tıp Fakültesi, Göztepe Eğitim Araştırma Hastanesi, Fiziksel Tıp ve Rehabilitasyon Anabilim Dalı, i̇stanbul, Türkiye Tel.: +90 2162802023 E-posta: drmadenci@yahoo.com Geliş Tarihi/Received: 07.04.2014 Kabul Tarihi/Accepted: 25.04.2014

Türk Osteoporoz Dergisi, Galenos Yayınevi tarafindan basılmıştır. / Turkish Journal of Osteoporosis, published by Galenos Publishing. 


\section{Giriş}

Osteoporoz (OP), kemik kitlesinin azalması, kalitesinin bozulması ve kırık riskinin artması ile karakterizedir (1). Hastaların yaşam kalitelerini etkileyebilmesi, uzun süreli ve pahalı tedavileri gerektiren komplikasyonlara hatta ölüme yol açabilmesi nedeniyle önemli bir halk sağlığı sorunudur. Kırık oluşması, klinik açıdan osteoporozun en önemli semptomudur (2).

Dünya Sağlık Örgütü (World Health Organization-WHO), kırık riskinin en önemli belirleyicisi olarak kabul edilen kemik mineral yoğunluğuna (KMY) dayanan daha objektif bir tanım ortaya koymuştur. Bu tanım, hastanın KMY'sinin aynı cins ve ırktaki genç erişkin popülasyonun ortalamasıyla karşılaştırılmasına dayanmaktadır. T skoru, normal genç erişkin için ortalama KMY'nin üstünde ve altındaki standart sapmadır $(2,3)$.

Tedaviye uyum $(4,5)$ iki alt başlık altında tanımlanabilir ve tedavinin başarılı olması için ikisinin de olması gerekir;

a. İtaat Etmek (Compliance): Hastanın randevularına uyumu, ilaç alımı gibi tıbbi önerilere uyması, yaşam şartlarını hastalığın ve tedavinin gerektirdiği şekilde düzenlemesi,

b. Uyum, Kooperasyon (Adherence): Hastanın yazılan ilacı olması gerektiği şekilde, miktarda ve sürede kullanması, sağlık kuruluşu randevularına düzenli gitmesi olarak tanımlanabilir.

Amaç hasta ve doktorun isteklerinin belirlenmesi, sorumlulukların paylaşılması, tedavi planı açısından iş birliğinin sağlanması olmalıdır. Hasta neyi, ne zaman, nerede, ne şekilde kullanacağını, nasıl yardım alacağını bilmelidir.

Uyum, medikasyon sahiplik oranı (MPR: medication possession ratio) kullanılarak hesaplanır. MPR=ilaç alınan gün sayısı/ alınması gereken gün sayısı'dır. Birçok çalışmada MPR \%80 ve üzerinde olduğunda iyi uyum olarak kabul edilirken (6-10), bazı çalışmalarda ise MPR'nin \%66 ve üzerinde olması iyi uyum olarak kabul edilmiştir $(11,12)$. Ilaç devamlılığı ise, tedavinin başlangııından tedavinin kesilmesine kadar olan zaman dilimi olarak açıklanabilir. Doksan gün ve üzeri ilaç almayan hastalar devamsız olarak kabul edilir (13).

Çalışmadaki amacımız, OP'li hastalar üzerinde Hasta Takip Programı́nın, ilaç uyumunu ve yaşam kalitesi üzerine etkisini araştırmaktır.

\section{Gereç ve Yöntem}

\section{Hasta Seçimi}

Çalışmaya OP tanısı, Dünya Sağlık Örgütü'nün (2) belirlediği DXA (Hologic QDR 4500) verileri kullanılarak $(14,15)$ konulan, yaş aralığı 50 ile 80 arası, 233 hasta (206 postmenopozal OP'li kadın ve 27 senil OP'li erkek) hasta alındı. Tek kör olarak 3 gruba, hastaların kullandıkları ilacın türü esas alınmadan günlük, haftalık ve aylık olarak ayrıldı (Şekil 1).

1. gruptaki hastaların kullandıkları ilaçlar: Strontium ranelate, Raloksifen, Kalsitonin (Günlük)

2. gruptaki hastaların kullandıkları ilaçlar: Alendronat, Risedronat (Haftalık)

3. gruptaki hastaların kullandıkları ilaçlar: Ibandronat, Risedronat (Aylik)
Hastaların ilaçlarının hatırlatılmaları 6 ay süreyle yapıldı. Her gün arama yapmanın hem arayan hem de aranılan kişi açısından uygun olmayacağı düşüncesi ile günlük ve haftalık grup için haftada bir kez telefonla arama yapıldı. Aylık grup için de ayda bir kez hatırlatma yapıldı. Her aramada ilaç kullanım bilgileri (ilaç kullanımının gecikmesi, bırakılması vb.) sorgulandı ve kaydedildi.

\section{Dışlama Kriterleri}

1. Telefon ile görüşme yapamıyor ise,

2. Hafıza problemi var ise,

3. Kendisine ulaşabileceğimiz bir telefonu yoksa,

4. Konuşması anlaşılır değilse,

5. Kanser veya başka ek olarak ağır bir hastalığı var ise,

6. OP tedavisi günlük, haftalık, aylık dışında başka bir tedavi alıyor ise,

7. Takibe başladıktan sonra hastaya telefon ile ulaşılamadı ise, 8. Grupların dağıımlarını etkileyebiledi ise.

Bu kriterlere göre 13'ü ilk ayda, diğer aylarda telefonla ulaşamadığımız ve grup dağıımını etkileyebileceğini düşündüğümüz 20 hastayı çalışma dışı bıraktık ve toplam 200 hasta (173 kadın ve 27 erkek) ile çalışmaya devam ettik. Sonuçlar ayrı ayrı tablolarda gösterildi. Aramalardaki başarı oranı \%100 tutuldu.

\section{Osteoporoz Anket Formu}

Tüm hastalara OP anket formu dolduruldu. Bu formu, hasta hakkında daha detaylı bilgi sahibi olmak ve grupları karşılaştırırken istatistiki analiz amaçıı kullanıldı.

Osteoporoz Anket Formu'nda; iletişim bilgileri, eğitim düzeyleri, medeni durumları, menapoz yaşı, mesleği, vücut kitle indeksi,

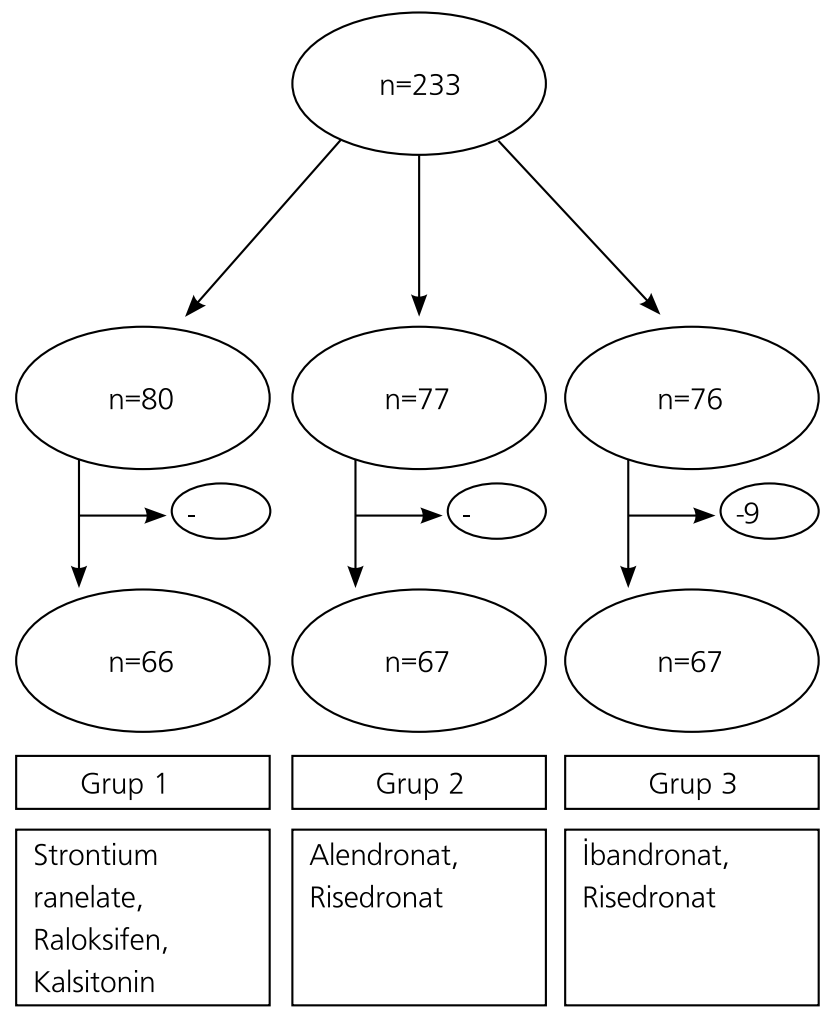

Şekil 1. Grupların dağılımları 
osteoporoz tanı yılı, tedaviye başlama tarihi, kullandığı osteoporoz ilaçları, kullanım şekli (günlük, haftalık veya aylık), eşlik eden hastalıkları ve kullandığı ilaçlar, gebelik sayısı, canlı doğum sayısı, çocuk sayısı, boy, kilo, şikayetlerinin kaç yıl önce başladığı, tanı konulan merkez, sigara ve alkol alışkanlığı, işinde zorlanma derecesi, geçirilmiş cerrahi öyküsü, ailede osteoporoz öyküsü, hekime ilk başvuru şikayeti, kırık değerlendirilmesi, fiziksel aktivite düzeylerini içermektedir.

\section{Hasta Takip Programı}

Program hastanın tedavisini, iletişim bilgilerini içeren, internet tabanlı ve her ortamda erişime açık, akılcı ilaç kullanımı düşünülerek hazırlanan, hastanın kullandığı ilaçları ve ne sıklıkla (günlük, haftalık, aylık gibi) kullanması gerektiği belirlendikten sonra ne zaman telefonla uyarılması gerektiğini hatırlatan özel bir programdır.

\section{Hasta İlaç Uyumu}

Hasta ilaç uyumunu değerlendirmek için MPR kullanıldı. MPR; ilaç kullanılan gün sayısının kullanılması gereken gün sayısına oranı olarak formüle edilmekte idi. MPR'de iyi uyum olarak \%80 ve üzerini, \%80 altı ise zayıf uyum olarak kabul ettik. Ortalama değerler tablolaştıııldı.

\section{Yaşam Kalitesi}

Qualeffo-41 tüm hastalara 0., 3. ve 6. aylarda aynı uzman doktor nezaretinde dolduruldu. Qualeffo-41 ölçeğindeki soruların yanıtları seçenek sırasıyla 1'den (sağlıklı) 5'e (sağlıksız) kadar puanlanmaktadır. Yirmi üç, 24, 25, 26. sorular için 1 ile 3 arasında; 27, 28 ve 29. sorular için ise 1 ile 4 arasında; kalan sorularda da 1-5 arasında puan verilmiş̧ir. Yirmi dört, 26 ve 29. sorular için 'bu soru benim için geçerli değil' ya da 'sinema veya tiyatroya gitmiyorum' seçenekleri için puan verilmemiştir. Otuz üç, 34, 35, 37, 39 ve 40. sorular puanlanırken, seçeneklerin sırası ters çevrilerek sıralamanın diğer sorularda olduğu gibi en iyi sağlık durumundan (1 puan), en kötü sağlık durumuna (5 puan) doğru olması sağlanmaktadır. Bölüm puanı ve toplam puan, puanların 100 üzerinden yapılan bir ölçüme aktarılmasıyla hesaplanmaktadır. Ölçekteki her bir alt grup ve toplam sonuç için, 0 puan en iyi sağlık durumunu gösterirken, 100 puan en kötü sağlık durumunu göstermektedir.

\section{İstatistik Analiz}

Uzman bir istatistik analizcisinden yardım alınarak yapılmıştır. Verilerin istatistik değerlendirilmesinde; sürekli değişkenlerin iki bağımsız grup karşılaştırımasında student $t$ testi, bağıml grupların karşılaştırılmasında paired t testleri kullanılmıştır. Sayısal değişkenler arasındaki korelasyon, pearson korelasyon katsayısı ile test edilmiştir. Tanıtıcı istatistik olarak frekans, yüzde ortalama \pm standart sapma değerleri verilmiştir. Kantitatif verilerin gruplar arası karşılaştırımasında, Mann-Whitney $U$ testi ve Kruskal-Wallis testi kullanılmıştır. İstatistiki analizler için SPSS for Windows version 16.0 paket programı kullanılmış ve $p \leq 0,05$ istatistiki olarak anlamlı kabul edilmiştir.

\section{Bulgular}

İki yüz otuz üç hasta ile çalışma başladı. Otuz üç hasta dışlama kriterleri gereği çalışma dışı bırakıldı. Hastaların yaş ortalamaları $64,7 \pm 8,85$ yıl, yaş aralığı 50 ve 80 yaş arasında ve cinsiyet dağılımları, 173 kadın ile 27 erkek idi. Çalışmaya devam eden hasta sayısı 200 idi. Hastaların \%64,5'i ev hanımı, \%16'sı işçi, $\% 19,5^{\prime} i$ memur ve diğer meslek gruplarındandı. Yüzde 77,5'i evli idi, diğer \%22,5'i ise yalnız yaşamakta idi. Eğitim düzeylerine bakıldığında \%50'ye yakınının okuma yazması yoktu. OP tedavi rejiminde 1. grup (günlük) 66 hasta, 2. grup (haftalık) 67 hasta ve 3. grup (aylık) 67 hasta idi ve demografik verileri karşılaştırıldığında istatistiki olarak anlamlı bir farklılık yoktu ( $p>0,05)$.

MPR değerlendirmesi 3 grupta, 6 aylık dönem içerisinde 2 . aydan itibaren başlangıca göre istatistiki olarak anlamlı fark saptandı (Tablo 1, $\mathrm{p}=0,001$ ).

Günlük tedavi (grup 1) 6 ay sonunda MPR değeri istatistiki olarak anlamlı idi (Tablo 2, p=0,001). Grup 2 ve 3'ün, grup 1 ile 6. aydaki MPR değerleri karşılaştırıldığında istatistiki olarak anlamlı fark gözlendi (Tablo 2, p=0,001). Grup 3 ile grup 2'nin 6. aydaki MPR değerleri karşılaştırılığında da istatistiki olarak anlamlı fark gözlendi (Tablo 2, p=0,001). Bu sonuçlara göre en uyumlu 3. grup (aylık) çıkmıştır.

Qualeffo-41'in alt başlığı olan sosyal işlevlerde başlangıca göre 3. ayda ve 6. ayda istatistiki olarak anlamlı düzelme mevcuttur (Tablo 3, p<0,05). Diğer alt başlıklarda ise anlamlı bir değişiklik saptanmamıştır (Tablo 3, p>0,05).

Yaşam kalitesi skoru ile MPR arasındaki ilişkiye bakıldığında istatistiki olarak anlamlı düzeyde ters korelasyon bulunmuştur $(p<0,001, r=-0,246)$.

\section{Tartışma}

Osteoporozda, kişilerin tedavilerine uyum oranlarının yaklaşık \%50 oranında olduğu çalışmalarda belirtilmiştir $(12,16)$. Bu problem diğer kronik hastalar için de geçerli bir sorun olmaktadır. OP'nin, sık görüldüğünü ve ciddi sonuçlara neden olabileceğini düşündüğümüzde erken tanının yanı sıra tedaviye uyumun da

\section{Tablo 1. Osteoporoz tedavi uyumunun gruplar arası karşılaştırılması}

\begin{tabular}{|l|l|l|l|l|l|l|l|l|l|l|}
\hline & MPR 1 & p 1 & MPR 2 & p 2 & MPR 3 & p 3 & MPR 4 & p 4 & MPR 5 & p 5 \\
\hline Grup 1 & $0,63 \pm 0,23$ & $0,023^{*}$ & $0,69 \pm 0,11$ & $0,004^{*}$ & $0,74 \pm 0,14$ & $0,001^{*}$ & $0,78 \pm 0,10$ & $0,001^{*}$ & $0,77 \pm 0,08$ & 0,001 * \\
\hline Grup 2 & $0,68 \pm 0,24$ & $0,001 *$ & $0,80 \pm 0,15$ & $0,001 *$ & $0,82 \pm 0,12$ & $0,001 *$ & $0,84 \pm 0,14$ & 0,001 * & $0,85 \pm 0,18$ & $0,001 *$ \\
\hline Grup 3 & $0,69 \pm 0,48$ & $0,001 *$ & $0,99 \pm 0,01$ & $0,001 *$ & $1,0 \pm 0,00$ & $0,001 *$ & $1,0 \pm 0,00$ & $0,001 *$ & $1,0 \pm 0,00$ & $0,001 *$ \\
\hline
\end{tabular}

*: İstatistik olarak anlamlı, Grup 1: Günlük, Grup 2: Haftalık, Grup 3: Aylık Grup, p 1, MPR'nin 2. aydaki değerinin başlangıç değerine göre değişiminin anlamllık düzeyi, p 2, MPR'nin 3. aydaki değerinin başlangıç değerine göre değişiminin anlamlılık düzeyi, p 3, MPR'nin 4. aydaki değerinin başlangıç değerine göre değişiminin anlamlılık düzeyi, p 4, MPR'nin 5. aydaki değerinin başlangıç değerine göre değişiminin anlamlılık düzeyi, p 5, MPR'nin 6 . aydaki değerinin başlangıç değerine göre değişiminin anlamlılık düzeyi 
önemi artmaktadır. OP tedavisine uyumun ve devamlılığın az olduğunu gösteren çalışmalar da mevcuttur. Bu çalışmalarda bir yıllık sürede tedaviye uyumun \%25-\%75 arasında olduğu, ortalama devamlıı̆̆ı ise 245 gün olduğu bildirilmiştir $(7,17)$. Tedaviye uyumun azalması, kaynakların gereksiz kullanılmasına bağlı sağlık harcamalarının artışına ve tedavi rejimlerinin uygun şekilde yerine getirilmemesinden kaynaklanan ilaç etkilerinin geç ortaya çıkmasına ve hastalık sürecinin uzamasına neden olduğu bilinmektedir (18).

Tedaviye uyumu arttıran faktörlerden birisi de doktorun hastasını bilgilendirmesidir. Malesef bir çalışmada, doktorların ancak üçte birinin hastalarını OP ile ilgili bilgilendirdiği, hasta ve risk altındaki kadınların çoğunun OP'nin ciddi bir hastalık olduğunun farkında olmalarına rağmen, \%80'inin kendisini risk altında görmediği ve Cal-D vitaminin olumlu etkisi konusunda farkındalıklarının düşük olduğu belirtilmiştir (19).

Son yıllarda yapılan araştırmalar osteoporotik kırıkların önemli bir kısmının osteopenik grupta olabileceğini göstermiştir (20). Sadece osteoporotik değil osteopenik hasta grubunda da kırık riskinin olması, bilgilendirilmesi gereken hasta grubunun yalnızca osteoporotik hasta grubu olmadığı gerçeğini de ortaya koymuştur.

OP, hastaların fiziksel ve psikososyal fonksiyonlarını da etkileyerek yaşam kalitelerinin azalmasına neden olabilmektedir $(21,22)$. OP'li hastaların yaşam kalitelerini değerlendirmek giderek önem kazanmış; yaşam kalitesi klinik çalışmaların bir ölçütü haline gelmiştir. Yaşam kalitesi ölçümü, klinik olarak tedavi stratejilerini saptamada ve tedavi etkinliğini değerlendirmede önemli bir yer tutmaktadır. Günümüzde, kronik hastalıklarda, hastaların yakınmalarını azaltmanın, hastalık belirtilerini ve komplikasyonlarını kontrol altına almanın yanı sıra, hastanın işlevsel, ruhsal, sosyal sağlığı ve yaşam kalitesini düzeltmeye yönelik girişimler de yapılmakta ve konuyla ilgili ölçümlere daha fazla yer verilmektedir. Biz de çalışmamızda Yaşam Kalitesi Anketi kullandık ve sosyal işlevlerde anlamlı derecede düzelme saptadık. Castelo-Branco ve ark.'nın (23) Cal-D vitamin tedavisinin uyumunun araştıııldığı çalışmada; uyumsuz hastaların eğitim düzeylerinin, tedaviye uyumu yüksek saptanan hastalardan daha düşük olduğu bildirilmiştir. Vytrisalova ve ark. (24) ise eğitim seviyesi ile tedaviye uyumun değişiklik göstermediğini bildirmişlerdir. Bizim çalışmamızda da eğitim ile tedavi uyumu arasında anlamlı düzeyde pozitif bir korelasyon çıkmıştır.

Uyum ile ilgili sayılabilecek en önemli faktörlerden biri de ilaç doz aralığıdır. Cramer ve ark. (7), Penning-van ve ark. (16) haftalık ilaç kullanan hastaların günlük ilaç kullanan hastalara göre ilaca uyum ve devamlılıkta daha iyi olduklarını belirtmişlerdir. Doz aralığının genişletilmesi ile ilaç kullanımına uyumun artabileceği düşüncesi üzerine haftada bir, ayda bir ve hatta yılda bir kez kullanılan antirezorptif ajanların kullanımının daha etkili olduğu gösterilmiştir $(10,19)$. Cotte ve ark. (25) 45 yaş üstü haftalık bifosfonat ve aylık ibandronat tedavisi başlanan hastalarda bir yıllık devamlılık ve uyumun aylık grupta daha yüksek olduğunu saptanmışlardır. Schnitzer ve ark. (26) günlük 10 mg alendronat ile haftalık $70 \mathrm{mg}$ alendronat kullanımını karşılaştırmışlar ve kısa doz aralığı yerine daha uzun doz aralığı ile ilaç almanın hastalar açısından daha uygun olduğunu ve uzun dönemde ilaç uyumunu olumlu yönde etkilediğini belirtmişlerdir. Cramer ve ark. (7) günlük ve haftalık bifosfonat kullanan hastalarda ilaç uyumunu araştırmışlar ve uyum oranlarını sırasıyla \%40 ile \%55 bulmuşlardır. Bizim çalışmamızda da aylık tedavi alanların uyumu haftalığa göre, haftalık tedavi alanların uyumu da günlüğe göre anlamlı çıkmıştır. Günlük tedavi de sıkı takip edildiğinde tedavi sonunda uyumlu çıkmıştır.

Shu ve ark. (27) hasta ve doktorlara osteoporoz teşhis ve tedavisi hakkında 3 ay süreli eğitim vermişler ve 10 ay sonraki MPR oranlarında ve devamlılıkta anlamlı bir fark görmüşlerdir. Bizim çalışmamızda da hastaların ilaçlarını almalarını kolaylaştırmak ve hatırlatmak amacıyla hastalar telefon aracılığıyla ilaç zamanı

\section{Tablo 2. Haftalık ve aylık grupların 6. ay sonunda günlük grupla MPR ilişkisinin karşılaştırılması}

\begin{tabular}{|l|l|l|l|l|l|}
\hline & & & \multicolumn{3}{|c|}{ MPR (ort \pm SD) } \\
\hline Gruplar & $\mathbf{n}$ & $\%$ & 1. ay & 6. ay & p \\
\hline Grup 1 & 66 & 33 & $0,63 \pm 0,23$ & $0,77 \pm 0,08$ & 0,001 * \\
\hline Grup 2 & 67 & 33,5 & $0,68 \pm 0,24$ & $0,85 \pm 0,18$ & $0,001 * *$ \\
\hline Grup 3 & 67 & 33,5 & $0,69 \pm 0,48$ & $1,0 \pm 0,00$ & $0,001 * * *$ \\
\hline *: Grup 1'in 1. ve 6. aydaki MPR karşlaştırması, **: Grup 2'nin 1. grup ile 6. ayda MPR karşıllaştırması, ***: Grup 3'ün 1. ve 2. grupla 6. ayda MPR karşıslaştırması \\
\hline
\end{tabular}

Tablo 3. Yaşam kalitesinin aylara göre değişimi

\begin{tabular}{|c|c|c|c|c|c|}
\hline & Ağrı & Sosyal İşlev & Sağlık & Zihinsel & Toplam-QUA \\
\hline $\mathrm{MPR} \pm \mathrm{SD}$ & $\begin{array}{l}48,21 \pm 20,30 * \\
50,81 \pm 20,49 * * \\
47,79 \pm 25,47^{* * *}\end{array}$ & $\begin{array}{l}51,68 \pm 26,13^{*} \\
46,45 \pm 21,47^{\star *} \\
56,85 \pm 25,15^{* * *}\end{array}$ & $\begin{array}{l}72,36 \pm 19,43^{*} \\
71,60 \pm 18,45^{* *} \\
71,68 \pm 19,74^{* * *}\end{array}$ & $\begin{array}{l}60,67 \pm 19,81^{*} \\
61,32 \pm 20,58^{* *} \\
60,61 \pm 21,85^{* * *}\end{array}$ & $\begin{array}{l}46,22 \pm 17,07^{*} \\
45,83 \pm 16,42^{* *} \\
46,76 \pm 18,99 * * *\end{array}$ \\
\hline$p$ & $\begin{array}{l}\text { p } 1=0,152 \\
\text { p } 2=0,823\end{array}$ & $\begin{array}{l}\text { p } 1=0,003 \\
\text { p } 2=0,004\end{array}$ & $\begin{array}{l}\text { p } 1=0,472 \\
\text { p } 2=0,620\end{array}$ & $\begin{array}{l}\text { p } 1=0,664 \\
\text { p } 2=0,978\end{array}$ & $\begin{array}{l}\text { p } 1=0,510 \\
\text { p } 2=0,609\end{array}$ \\
\hline
\end{tabular}


geldiğinde düzenli olarak aranmış, 6 ay süre ile takip edilmiş ve MPR'lerinde başlangıca göre anlamlı düzeyde artış saptanmıştır. OP tedavisi uzun kronik bir hastalık olup, kırık riskini arttırması, sosyal, psikolojik, ekonomik ve fiziksel boyutları ile yaşam kalitesini olumsuz etkilerinin olması nedenleriyle önemli bir halk sağlığı sorunudur. Bu nedenle ilaç tedavisine uyum büyük önem arz etmektedir.

\section{Sonuç}

Hastaların kullanmış oldukları ilaçların doz aralıklarının özellikle uzun doz aralıklı ilaç rejimlerinin ve hasta ilaç hatırlatma programlarının uyum üzerine çok etkili olduğunu ve uyumun artması ile yaşam kalitesinin de daha iyi olacağını söyleyebiliriz. Tedavi uyumu bozulursa tıbbi zararlara, ekonomik kayıplara neden olunabileceği de unutulmamalıdır.

\section{Kaynaklar}

1. Morgan SL SK. Osteoporotic bone diseases. WJ K, editor. Philadelphia: Lippicott Williams, Wilkins; 2001.

2. Series WTR. Assessment of Fracture Risk and its Application to screening for Postmenopausal Osteoporosis 1994;843:1-129.

3. Kanis JA. Assessment of fracture risk and its application to screening for postmenopausal osteoporosis: synopsis of a WHO report. WHO Study Group. Osteoporos Int 1994;4:368-81.

4. Cuneo WD, Snider DE Jr. Enhancing patient compliance with tuberculosis therapy. Clin Chest Med 1989;10:375-80.

5. Morisky DE, Malotte CK, Choi P, Davidson P, Rigler S, Sugland B, et al. A patient education program to improve adherence rates with antituberculosis drug regimens. Health Educ Q 1990;17:253-67.

6. Caro JJ, Ishak KJ, Huybrechts KF, Raggio G, Naujoks C. The impact of compliance with osteoporosis therapy on fracture rates in actual practice. Osteoporos Int 2004;15:1003-8.

7. Cramer JA, Amonkar MM, Hebborn A, Altman R. Compliance and persistence with bisphosphonate dosing regimens among women with postmenopausal osteoporosis. Curr Med Res Opin 2005:21:1453-60.

8. Huybrechts KF, Ishak KJ, Caro JJ. Assessment of compliance with osteoporosis treatment and its consequences in a managed care population. Bone 2006;38:922-8.

9. Recker RR, Gallagher R, MacCosbe PE. Effect of dosing frequency on bisphosphonate medication adherence in a large longitudina cohort of women. Mayo Clin Proc 2005;80:856-61.

10. Sambrook P. Compliance with treatment in osteoporosis patients an ongoing problem. Aust Fam Physician 2006;35:135-7.

11. Yood RA, Emani S, Reed Jl, Lewis BE, Charpentier M, Lydick E. Compliance with pharmacologic therapy for osteoporosis. Osteoporos Int 2003;14:965-8.
12. Solomon DH AJ, Katz JN, Finkelstein JS, Arnold M, Polinski JM, et al. Compliance with osteoporosis medications. Arch Intern Med 2005;2414-9

13. Weycker D, Macarios D, Edelsberg J, Oster G. Compliance with drug therapy for postmenopausal osteoporosis. Osteoporos Int 2006:17:1645-52

14. Kanis JA, Gluer CC. An update on the diagnosis and assessment of osteoporosis with densitometry. Committee of Scientific Advisors, International Osteoporosis Foundation. Osteoporos Int 2000;11:192-202.

15. Rosen CJ. Clinical practice. Postmenopausal osteoporosis. N Engl J Med 2005;353:595-603.

16. Penning-van Beest FJ GW, Erkens JA, Herings RM. Determinants of persistence with bisphosphonates: a study in women with postmenopausal osteoporosis. Clin Ther 2006;28:236-42. 17.

17. Siris ES, Harris ST, Rosen CJ, Barr CE, Arvesen JN, Abbott TA, et al. Adherence to bisphosphonate therapy and fracture rates in osteoporotic women: relationship to vertebral and nonvertebral fractures from 2 US claims databases. Mayo Clin Proc 2006;81:1013-22.

18. Kyngas H, Duffy ME, Kroll T. Conceptual analysis of compliance. J Clin Nurs 2000:9:5-12.

19. Boonen S, Rizzoli R, Meunier PJ, Stone M, Nuki G, Syversen U, et al. The need for clinical guidance in the use of calcium and vitamin $D$ in the management of osteoporosis: a consensus report. Osteoporos Int 2004;15:511-9.

20. OS A. FRAX ve Türkiye Osteoporotik kırık riski hesaplanması. Eklem Hastalik Cerrahisi 2008;19:100.

21. Cox D FR, Fletcher A. Quality of life assessment: Can we keep it simple. J Stat Soc 1992;155:353-93.

22. De la Loge $C$, Sullivan K, Pinkney R, Marquis $P$, Roux $C$, Meunier PJ. Cross-cultural validation and analysis of responsiveness of the QUALIOST: QUAlity of Life questionnaire In OSTeoporosis. Health Qual Life Outcomes 2005;3:69.

23. Castelo-Branco C, Cortes X, Ferrer M. Treatment persistence and compliance with a combination of calcium and vitamin D. Climacteric 2009:13:578-84

24. Vytrisalova M, Blazkova S, Palicka V, Vlcek J, Cejkova M, Hala $T$, et al. Self-reported compliance with osteoporosis medicationqualitative aspects and correlates. Maturitas 2008;60:223-9

25. Cotte FE, Fardellone P, Mercier F, Gaudin AF, Roux C. Adherence to monthly and weekly oral bisphosphonates in women with osteoporosis. Osteoporos Int 2010;21:145-55.

26. Schnitzer T, Bone HG, Crepaldi G, Adami S, McClung M, Kiel D, et al. Therapeutic equivalence of alendronate $70 \mathrm{mg}$ once-weekly and alendronate $10 \mathrm{mg}$ daily in the treatment of osteoporosis. Alendronate Once-Weekly Study Group. Aging (Milano) 2000;12:1-12.

27. Shu AD, Stedman MR, Polinski JM, Jan SA, Patel M, Truppo C, et al. Adherence to osteoporosis medications after patient and physician brief education: post hoc analysis of a randomized controlled trial. Am J Manag Care 2009;15:417-24. 